\title{
The pattern of injury in fatal pedal cycle accidents and the possible benefits of cycle helmets
}

\author{
Alexander Kennedy
}

\begin{abstract}
Objective-To establish the number of fatal pedal cycle accidents occurring in the Sheffield and Barnsley area, UK, and to investigate the possible benefits of helmet wearing by cyclists.

Design-All medicolegal investigations into fatal road traffic accidents in the areas of Sheffield and Barnsley (total population 757300 ) were reviewed to identify cases in which pedal cyclists had died. The necropsy reports of the cases were compared with those of an equal number of controls (pedestrians and motor vehicle occupants) which were matched by sex, age and year of death.
\end{abstract}

Results-28 deaths occurred in the last 15 years giving a mortality of $0 \cdot 25 / 100000$ per annum, which is lower than the rate for the $\mathrm{UK}$ as a whole $(0 \cdot 43 / 100000)$, but in five cases the accidents which eventually led to death occurred outside the area under study. These deaths represented $3 \cdot 3 \%$ of road traffic deaths between 1979 and 1993. Over $80 \%$ of both cases and controls had severe head injuries, but the controls had suffered more fatal injuries to other parts of the body. None of the cyclists had worn helmets and, in order to assess the maximum possible benefit of helmet wearing, it was assumed that a helmet would have saved all those who only had head injuries. It was found that helmets might have saved 14 lives in 15 years. A similar calculation based on the controls suggests that if all pedestrians and vehicle occupants had worn helmets, 175 lives might have been saved in the same period.

Conclusions-There is no justification for compelling cyclists to wear helmets without taking steps to improve the safety of all road users.

(Br F Sports Med 1996;30:130-133)

Key terms: cyclists; fatal accidents; safety helmet

Although there are many non-fatal cycle accidents, many of which are never reported, deaths are quite uncommon and there are few pathological studies of the injuries involved. Surveys in Florida, ${ }^{1}$ Italy, ${ }^{2}$ Brisbane, ${ }^{3}$ Sweden, ${ }^{4}$ and New Zealand ${ }^{6}$ all reported a high incidence of head injuries. None of these studies is from the United Kingdom, where the incidence of head injuries in fatal cycle accidents is estimated to be $70 \%{ }^{7}$ Furthermore none of the studies quoted allowed for the analysis of the effects of multiple injuries, and without such information it is not possible to make an assessment of the possible value of cycle helmets in preventing death. In view of these gaps in our knowledge it was decided to examine the fatal cycle accidents in the Sheffield area in order to establish their frequency, the presence of any secular trend, and the possible benefits of helmet wearing as deduced from the pattern of injury.

\section{Methods}

The lists of all medicolegal investigations into deaths occurring in the area of Sheffield and Barnsley during the years 1979-1993 were screened to identify deaths arising as a result of road traffic accidents and the pedal cycle accidents were identified. For each death of a pedal cyclist a control was selected matched by sex and, as closely as possible, by age and year of death from among the pedestrians and motor vehicle occupants.

After the cases and controls had been identified, the necropsy reports were studied to establish the pathologists' conclusions as to the cause of death, the individual major injuries involving the skull, brain, spinal cord, thoracic cage, lungs, great vessels, and abdominal viscera. From the sites and nature of the injuries found in each case it was possible to identify deaths which might or which could not have been prevented had a helmet been worn.

Population figures estimated for mid 1993 were obtained from the Sheffield Health Authority. Figures for volumes of cycle traffic were provided by the Road Safety Unit of Sheffield City Council.

\section{Results}

A total of 28 necropsy reports relating to cycling deaths was found (table 1); these amounted to $3.3 \%$ of all traffic fatalities during the 15 year period studied. The annual number of road traffic deaths fell over this period of

Table 1 Numbers of road traffic deaths in Sheffield and Barnsley 1979-1993 in three-year periods (percentages in brackets).

\begin{tabular}{lccccc}
\hline Years & Pedestrians & Cyclists & $\begin{array}{l}\text { Motor } \\
\text { cyclists }\end{array}$ & $\begin{array}{l}\text { Motor } \\
\text { vehicle } \\
\text { occupants }\end{array}$ & Totals \\
\hline $1979 / 81$ & 96 & 4 & 44 & 60 & 204 \\
& $(47)$ & $(2)$ & $(22)$ & $(29)$ & \\
$1982 / 84$ & 87 & 4 & 27 & 57 & 175 \\
& $(50)$ & $(2 \cdot 3)$ & $(15)$ & $(33)$ & \\
$1985 / 87$ & 74 & 6 & 24 & 51 & 155 \\
& $(48)$ & $(3 \cdot 9)$ & $(15)$ & $(33)$ & 157 \\
$1988 / 90$ & 78 & 8 & 19 & 52 & 157 \\
& $(50)$ & $(5 \cdot 1)$ & $(12)$ & $(33)$ & 154 \\
$1991 / 93$ & 63 & 6 & 17 & 68 & 154 \\
& $(41)$ & $(3 \cdot 9)$ & $(11)$ & $(44)$ & \\
Totals & 398 & 28 & 131 & 288 & 845 \\
& $(47)$ & $(3 \cdot 3)$ & $(16)$ & $(34)$ & \\
\hline
\end{tabular}


Table 2 Adults and juvenile (less than 18) cyclists killed in Sheffield and Barnsley 1979-93 (percentages in brackets)

\begin{tabular}{lccr}
\hline Years & fuveniles & Adults & Total \\
\hline $1979-81$ & 3 & 1 & 4 \\
$1982-84$ & $(75)$ & $(25)$ & 4 \\
& 2 & 2 & \\
$1985-87$ & $(50)$ & 2 & 6 \\
$1988-90$ & $(66 \cdot 6)$ & $(33 \cdot 3)$ & \\
$1991-93$ & 4 & 4 & 8 \\
& $(50)$ & $(50)$ & 6 \\
Totals & $(0)$ & $(100)$ & \\
& 13 & 15 & 28 \\
& $(46 \cdot 4)$ & $(53 \cdot 6)$ & $(100)$ \\
\hline
\end{tabular}

time and the most notable falls were amongst the pedestrians and motorcyclists, but the number and proportion of cyclists killed rose.

The mid-year estimated populations for 1993 was 757300 for Sheffield and Barnsley. Therefore the fatality rate was 0.25 per 100000 per annum. This compares with a total of 242 cycling deaths in the UK as a whole in 1991 , which is a rate of $0.43 / 100000 .^{8}$ All but four of the victims were male and $46.4 \%$ were under the age of 18 years (table 2) but all those killed in the past three years were adults.

THE INJURIES

The anatomical distribution of the sites of serious injury is summarised in table 3. Similar numbers of cyclists and controls suffered serious head injuries, which included skull fractures, subdural and subarachnoid haemorrhage, cerebral contusions, lacerations, oedema, and in some cases uncal or cerebellar herniation. Five cyclists were killed without suffering significant head injuries; the causes of death in these five cases were transection of the spinal cord in four and a crush injury of the chest which ruptured the aorta in the fifth. The injuries in this last case were a result of crushing by the wheel of a heavy goods vehicle (HGV).

Eight cyclists suffered spinal injuries, six of which involved the cervical spine and among these there were two cases of atlanto-occipital dislocation. In the other two cases the dorsal spine was damaged and, in one of these, death occurred nine years after the accident as a result of the urinary complications of the injury to the dorsal cord.

These findings are in agreement with those of Fife $e t a l^{1}$ who found that, in cycling accidents, spinal injuries decrease in frequency further down the vertebral column.

Over one third of cyclists had major thoracic injuries. Seven had large haemothoraces; 11 had multiple fractures of the ribs and sternum, five had lacerations of the lung, and two had lacerations of the heart or disruption of the aorta. These severe injuries were not confined

Table 3 Number of fatal injuries found at necropsy in cyclists and controls (percentages in brackets)

\begin{tabular}{lrc}
\hline & Cyclists & $\begin{array}{l}\text { Controls (Pedestrians } \\
\text { and vehicle occupants) }\end{array}$ \\
\hline Cranial & $23(82)$ & $24(86)$ \\
Spinal & $8(29)$ & $8(29)$ \\
Thoracic & $11(39)$ & $20(71)$ \\
Abdominal & $4(14)$ & $8(29)$ \\
\hline
\end{tabular}

Table 4 The relation between the lethal injuries and the type of accident in 27 cases (percentages in brackets)

\begin{tabular}{lccc}
\hline & $\begin{array}{l}\text { Solo } \\
\text { accidents }\end{array}$ & $\begin{array}{l}\text { Impact with } \\
\text { cars and } \\
\text { motorcycles }\end{array}$ & $\begin{array}{l}\text { Impact with } \\
\text { HGVs and } \\
\text { PSVs }\end{array}$ \\
\hline No of cases & 5 & 17 & 5 \\
Cranial & 4 & 15 & 3 \\
Spinal & $(80)$ & $(88)$ & $(60)$ \\
Thoracic & 2 & 6 & 0 \\
Abdominal & $(40)$ & $(35)$ & 4 \\
& $(40)$ & 5 & $(80)$ \\
& 0 & $(29)$ & 2 \\
\hline
\end{tabular}

HGV, heavy goods vehicle; PSV, public service vehicle.

to cyclists who had collided with motor vehicles.

The only fatal abdominal injuries were four cases of laceration of the liver and all of these had been hit by motor vehicles.

\section{THE RELATION BETWEEN THE INJURIES AND} THE TYPE OF ACCIDENT

For one of the cases who died nine years after the original accident the details of the accident were not available; the findings in the remaining 27 cases are summarised in table 4 .

In solo accidents, in which no other moving vehicle had been involved, the cyclists had fallen off and hit the road, street furniture, or a stationary vehicle. There were five accidents of this type and four of them had severe head injuries, two had fatal fractures of the cervical spine, and two had multiple fractures of the ribs with haemothoraces.

The group of 17 cases who had been hit by motor vehicles had the highest incidence of severe head injuries but they also had more widespread damage to the spine, chest, and abdomen.

Four cyclists had collided with HGVs and one with a public service vehicle (PSV). There were only three injuries in this group but there were massive injuries of the chest, abdomen, and limbs caused by crushing.

\section{Discussion}

During the period under study, the number of fatal cycle accidents was well below the national average for the United Kingdom, less than the rate of 0.5 in the USA, ${ }^{9}$ and well below the figure of 1.6 which may be calculated for northern Sweden. ${ }^{10}$ The true fatality rate is below the figure of 0.25 given above as, in some cases, the accident leading to death took place outside South Yorkshire, although the deaths occurred within the county. In one case, mentioned above, the accident had taken place before the beginning of the 15 year period studied. The obvious reason for this low fatality rate is that the area is hilly and this dissuades many people from cycling at all so that there are fewer cyclists at risk.

The total number of road deaths in the area studied fell throughout the 15 years (table 2) but the annual numbers and proportions of cyclists rose from $2 \%$ of the total to a peak of $5 \cdot 1 \%$ in $1988 / 90$, followed by a fall to $3.9 \%$ in the last three years. The changes in the number of cycle journeys made are shown in table 5 . Using 1984, the earliest year for which counts 
Table 5 The changes in the number of cyclists entering the centre of Sheffield, counted each autumn $(1984=1 \cdot 00)$.

\begin{tabular}{ll}
\hline Year & Factor based on 1984 \\
\hline 1985 & $1 \cdot 11$ \\
1986 & 1.45 \\
1987 & 1.74 \\
1988 & 1.51 \\
1989 & 1.94 \\
1990 & 1.88 \\
1991 & 1.93 \\
1992 & 1.93 \\
1993 & 1.62 \\
\hline
\end{tabular}

are available as a baseline, the number of cyclists nearly doubled by 1989 but since then there has been a fall back to 1.62 times the baseline figure of 1455 cyclists. This suggests that the trends in fatal cycle accidents follow the trends in cycle usage and, that if cycling is to be encouraged, then additional safety measures will have to be taken to prevent a rise in the number of casualties.

The second notable feature is that nearly half the fatalities were juveniles. Spence and colleagues reported a mortality of 1.44 deaths per 100000 children on Ontario and in $89 \%$ of these head injuries were considered to be responsible. ${ }^{11}$ In $96 \%$ of deaths the cause was a collision with a motor vehicle. Similarly Sacks et al studied a five year period in the USA and found that $62 \%$ of all cycling deaths were due to head injuries and that $76 \%$ of head injury deaths were children under the age of $15 .^{12}$

Even in the solo accidents which involved no other moving vehicle the injuries were quite severe (table 4), although they were limited to the head, neck, and thorax. There were four massive skull fractures, two fractures of the cervical spine at $\mathrm{C} 4 / 5$ and $\mathrm{C} 6 / 7$, and one case of multiple rib fractures. The severity of some of these injuries may be explained by the hilly nature of the terrain for in three of these cases, including one in which the accident occurred outside Yorkshire, the cyclists were descending hills. High speeds are easily obtainable in some of the long descents out of the Pennine hills so that impacts may occur at speeds which are similar to those in accidents involving motorised vehicles and the injuries are accordingly severe.

Collisions with cars or heavy vehicles produced severe injuries to the trunk by blunt impact or by crushing. It was in these groups that there were lacerations of the lungs, heart, aorta, and liver so that survival was unlikely even if helmets had been worn. In all, half of the cyclists had lethal injuries to the trunk or spinal cord. None of the cyclists had worn helmets but if it is assumed that helmets would have been $100 \%$ effective in preventing head injury, the maximum number of lives which might have been saved would have been 14, which is the number in which the major injuries were limited to the head. This is the best possible estimate of the life saving potential of helmets but even those who are strong advocates of helmet wearing found that approved helmets reduced the proportion of head injuries by only $45 \% .{ }^{13}$ Bjornstig et al concluded that helmets would have had an injury reducing effect in two of every five fatal cases. ${ }^{14}$ Wood and Milne found that $80 \%$ of bicycle fatalities were caused by head injuries and that head injury rates in Victoria had fallen following legislation but these findings made no allowance for any changes in cycle usage which may have been caused by the compulsory wearing of helmets. ${ }^{15}$

The controls had a similar number of head injuries but in addition they suffered more widespread damage than the cyclists (table 3 ). In only eight of the controls $(28 \%)$ were the injuries limited to the head, but if the same reasoning is applied as in the case of the cyclists then eight lives might have been saved had helmets been worn. The difference is that while fatal cycle accidents are uncommon, deaths of pedestrians and vehicle occupants are very common, so that if the figure of $28 \%$ is applied to columns 2 and 5 of table 1 then it may be argued that the lives of over 170 pedestrians and vehicle occupants might have been saved. This conclusion is in good agreement with the findings of Hillman, who concluded that cyclists account for only one in 12 of all road fatalities which result from head injury. ${ }^{16}$ Deaths of cyclists are only a minor part of the road traffic accident problem but it seems unreasonable to propose that all road users should be compelled to wear helmets. A more sensible approach would be to reduce vehicle speeds and traffic volumes as well as providing safer routes for cyclists and pedestrians; it may be necessary to apply special restrictions to HGVs in urban areas. ${ }^{17}$

As none of the cyclists in this series wore helmets it is not possible to say whether there are any disadvantages to helmet wearing, but the bulk of the published evidence - based upon non-fatal accidents - indicates the helmets provide some protection against injury to the head and, in the series reported by Spaite et al, helmet users seemed to have fewer injuries to other parts of the body. ${ }^{9}$ The wearing of a helmet makes a cyclist much more conspicuous and so it may act as a primary preventive measure. The adverse effects of risk compensation are fully discussed by Hillman ${ }^{16}$ and the only other way in which helmets might be disadvantageous is by increasing the amount of energy transferred to the cervical spine in the event of a crash, so increasing the risk of spinal injury.

The results of the present series indicate that, at best, helmets could only have saved $50 \%$ of the deaths and that other measures, directed at making roads safer, are required to improve on this figure. Particular attention needs to be given to the training and supervision of juvenile cyclists. Helmets may have a part to play but we need to put more effort into the primary prevention of accidents as recommended by McCarthy. ${ }^{17}$

I am greatly indebted to Mrs M Turner and her staff of Sheffield Archives, HM Coroner Mr C Dorries and his staff, as well as the many pathologists who gave permission to abstract their necropsy reports. The data on cycle flows were provided by $\mathrm{Mr}$ Paul Lizzi of the Road Safety Unit, Sheffield City Council. Mrs L A Norcliffe processed the manuscript.

1 Fife D, Davis J, Tate L, Wells JK, Mohan D, Williams A Fatal injuries to bicyclists: the experience of Dade County Florida. $\mathcal{F}$ Trauma 1983;23:745-55. 
2 Gennari M, Laudano M. Fatal motorcycle, motorbike and bicycle accidents. Cases from the medico-legal sector of Parma. Acta BioMed 1986;57:53-61.

3 Nixon J, Clacher R, Pearn J, Corcoran A. Bicycle accidents in childhood. BMF 1987;294:1267-9.

4 Lutz, St Kreidel H. Fatal bicycle accidents - causes and legal responsibility. F Legal Med 1988;101:1-8.

5 Ostrom M, Bjornstig U, Naslund K, Eriksson A. Pedal cycling fatalities in northern Sweden. Int $f$ Epidemiol cycling fatalities

6 Collins BA, Langley JD, Marshall SW. Injuries to pedal cyclists resulting in death and hospitalisation. NZ Med $\mathcal{F}$ 1993;106:514-6.

7 Parliamentary Advisory Council on Transport Safety. Road accidents in focus. 7. Pedal cyclists. 1992.

8 Gilbert $\mathrm{K}$, McCarthy M. Deaths of cyclists in London 1985-92: the hazards of road traffic. $B M F 1994 ; 308$ 1534-7.

9 Spaite DW, Murphy M, Criss EA, Valenzuela TD, Meislin HW. A prospective analysis of injury severity among helmeted and nonhelmeted bicyclists involved in collisions with motor vehicles. f Trauma 1991;31: 1510-6.
10 Lind MG, Wollin S. Bicycle accidents. Acta Chir Scand (suppl) 1986;531:1-47.

11 Spence LJ, Dykes EH, Bohn DJ, Wesson DE. Fatal bicycle accidents in children: a plea for prevention. $\mathcal{F}$ Pediatr Surg 1993;28:214-6.

12 Sacks JJ, Holmgreen P, Smith SM, Sosin DM. Bicycleassociated head injuries and deaths in the United States from 1984 through 1988 . How many are preventable? fAMA 1991;266:3016-8.

13 McDermott FT, Lane JC, Brazenor GA, Debney EA. The effectiveness of bicyclist helmets: a study of 1710 effectiveness of bicyclist helmets: a study of 1710

14 Bjornstig U, Ostrom M, Eriksson A, Sonntag-Ostrom E. Head and face injuries in bicyclists - with special reference to possible effects of helmet use. $\mathcal{F}$ Trauma 1992;33 887-93.

15 Wood T, Milne P. Head injuries to pedal cylists and the promotion of helmet use in Victoria, Australia. Accid Anal Prev 1988;20:177-85.

16 Hillman M. Cycle helmets: the case for and against. London: Policy Studies Institute, 1993.

17 McCarthy M. Pedal cyclists, crash helmets and risk. Public Health 1991;105:327-34.

\section{New stock to order}

Sweaters Lambswool fine knit, V-neck or round $£ 32+£ 1 \mathrm{p} \& \mathrm{p}$

Ladies scarves White with blue border and BASM logo $-\quad £ 5+£ 1 \mathrm{p} \& \mathrm{p}$ 27-inch square

Navy blue with fringe and BASM logo

$£ 5+£ 1 p \& p$

Ties

Single motif

$£ 6+£ 1 \mathrm{p} \& \mathrm{p}$

Blazer badge

Wire -4 inches high $£ 6+£ 1 p \& p$

Wire -3 inches high

$\begin{array}{ll}\text { Slipovers } & \text { Lambswool fine knit, V-neck, with small } \\ \text { motif. Machine washable. State colour }\end{array}$ neck with small motif. Machine washable.

State colour and chest size required. and chest size required.

Sweatshirts With small motif.

State colour and chest size required.

Polo shirts

With small motif.

State colour and chest size required.

Send orders to John H Clegg JP LDS RCS Eng, Hon Secretary, Birch Lea, 67 Springfield Lane, Eccleston, St Helens, Merseyside WA10 5HB, UK. (Tel: 01744 28198) 